\title{
Abundance and Speciation of Surface Oxygen on Nanosized Platinum Catalysts and Effect on Catalytic Activity
}

\author{
Rui Serra-Maia, ${ }^{\dagger}$ Christopher Winkler, $^{\S}$ Mitsushiro Murayama, ${ }^{\S} \ddagger$ Kevin Tranhuu, $^{\dagger}$ \\ and F. Marc Michel* ${ }^{\dagger} \odot$

\begin{abstract}
${ }^{\dagger}$ Department of Geosciences, Virginia Polytechnic Institute and State University, Blacksburg Virginia 24061, United States
${ }^{\ddagger}$ Department of Materials Science and Engineering, Virginia Polytechnic Institute and State University, Blacksburg Virginia 24061, United States

${ }^{\S}$ Institute of Critical Technology and Applied Science, Virginia Polytechnic Institute and State University, Blacksburg Virginia 24061, United States
\end{abstract}

Supporting Information

\begin{abstract}
Oxygen at the surface of nanosized platinum has a direct effect on catalytic activity of oxidation-reduction chemical reactions. However, the abundance and speciation of oxygen remain uncertain for platinum with different particle size and shape characteristics, which has hindered the development of fundamental propertyactivity relationships. We have characterized two commercially available platinum nanocatalysts known as Pt black and Pt nanopowder to evaluate the effects of synthesis and heating conditions on the physical and surface chemical properties, as well as on catalytic activity. Characterization using complementary electron microscopy, X-ray scattering, and spectroscopic methods showed that the larger average crystallite size of Pt nanopowder $(23 \mathrm{~nm})$ compared to Pt black $(11 \mathrm{~nm})$ corresponds with a $70 \%$ greater

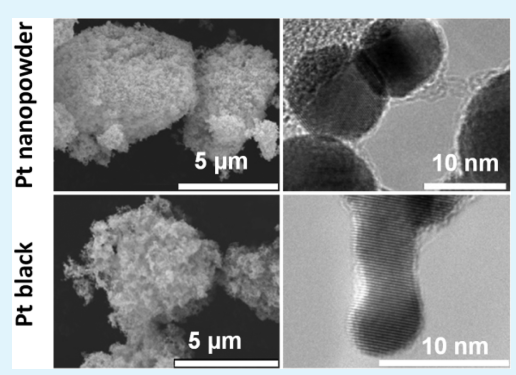
surface oxygen concentration. Heating the samples in air resulted in an increase in surface oxygen concentration for both nanocatalysts. Surface oxygen associated with platinum is in the form of chemisorbed oxygen, and no significant amounts of chemically bonded platinum oxide were found for any of the samples. The increase in surface oxygen abundance during heating depends on the initial size and surface oxygen content. Hydrogen peroxide decomposition rate measurements showed that larger particle size and higher surface chemisorbed oxygen correlate with enhanced catalytic activity. These results are particularly important for future studies that aim to relate the properties of platinum, or other metal nanocatalysts, with surface reactivity.
\end{abstract}

KEYWORDS: surface oxygen, particle size, X-ray photoelectron spectroscopy (XPS), Rietveld analysis, catalytic activity

\section{INTRODUCTION}

Understanding property-activity relationships for metal nanoparticles is one of the greatest challenges in the design of heterogeneous catalysts. ${ }^{\text {. }}$ This includes colloidal forms of metallic nanocatalysts currently used in a wide range of applications. $^{2-8}$ Surface chemical composition is a critical factor in nanocatalyst reactivity because it directly affects the type and strength of chemical bonds that can be established with reactants in solution. ${ }^{9}$ Crystallite size and shape are also important because of their effects on lattice strain and the work function of metal nanoparticles, which directly influence surface electronic properties. ${ }^{10}$ The physical and surface chemical properties of metal nanocatalysts are initially determined by the conditions of synthesis. Further modifications of properties can occur from subsequent sample treatments, such as heating, or during chemical reactions due to the interaction of the particle surfaces with a surrounding medium. ${ }^{11-13}$ However, these effects are not usually accounted for in experimental studies aimed at developing propertyactivity relationships. This has been the case for platinum $(\mathrm{Pt})$, an important and effective nanocatalyst used in colloidal form in a wide variety of industrial and technical applications. ${ }^{2,14-19}$ Overall, the reported physicochemical properties of $\mathrm{Pt}$ nanocatalysts vary widely for different synthesis methods and studies, which has direct implications in their catalytic activity. ${ }^{20-23}$ Here, we report detailed characterization results and compare the catalytic activity of two different types of commercially available unsupported Pt nanocatalysts. Selected background information is given for the samples that are the focus of the present study.

1.1. Platinum Black. Platinum black (Pt black) is a form of synthetic nanosized $\mathrm{Pt}$ that has long been recognized for its outstanding catalytic activity. ${ }^{24,25}$ It is typically synthesized by heating $\mathrm{H}_{2} \mathrm{PtCl}_{6}$ to approximately $450{ }^{\circ} \mathrm{C}$ to form $\mathrm{PtO}_{2}$ followed by hydrogenation in an aqueous suspension to form metallic Pt black. ${ }^{24,26-40}$ Alternative synthesis routes involve reaction of $\mathrm{H}_{2} \mathrm{PtCl}_{6}$ or $\mathrm{K}_{2} \mathrm{PtCl}_{6}$ with formaldehyde in a potassium hydroxide solution. ${ }^{38}$ To reduce loss of catalyst

Received: March 26, 2018

Accepted: June 4, 2018

Published: June 4, 2018 
material, in applications such as fuel cells, electrochemical precipitation of $\mathrm{Pt}$ onto the surface of electrodes to form platinized platinum is also used. ${ }^{21,32,41-46}$ When the deposited product has the characteristic black color, the term "Pt black" is often used in place of platinized platinum..$^{21,26,32}$ A summary of synthesis methods, physicochemical characteristics, and uses of Pt black from selected studies is provided in Supporting Information Table S1.

Pt black aggregates are generally characterized by a dendritic morphology ${ }^{21,34,41,45}$ with rounded nanocrystals ${ }^{39}$ and crystallite sizes ranging between 5 and $12 \mathrm{~nm} .^{39,46}$ The specific surface area (SSA) based on the Brunauer-Emmett-Teller (BET) method ranges from 10 to $30 \mathrm{~m}^{2} / \mathrm{g}^{23,28,31-33,37,46}$ Sintering, crystallite growth, and the loss of fractal features has been reported for Pt black at temperatures as low as 360 ${ }^{\circ} \mathrm{C} .{ }^{41,46}$

There are limited data and a lack of consensus in the literature regarding the surface and bulk chemical compositions of Pt black. Early studies suggested that surface oxygen content varies from 2 to $20 \%\left(\mathrm{~mol}_{\mathrm{O}} / \mathrm{mol}_{\mathrm{Pt}}\right) \cdot{ }^{24,25}$ More recent XPS analyses confirm the presence of oxygen at the surface of Pt black, but the speciation and concentration are seldom discussed. ${ }^{47-49}$

1.2. Platinum Nanopowder. Platinum "nanopowder" and "nanoparticles" (hereinafter referred to as Pt nanopowder) are Pt nanocatalysts with renowned catalytic activity. It is usually synthesized by chemical vapor deposition, due to high size and shape control, ${ }^{27}$ for uses such as proton exchange membrane (PEM) fuel cells, ${ }^{50}$ integrated circuits, and optical applications. ${ }^{51}$ Pt nanopowder is typically lighter in color than the distinctive dark gray to black color of Pt black. A summary of synthesis methods, physicochemical characteristics, and applications of $\mathrm{Pt}$ nanopowder from selected studies is provided in Table S2.

The reported physical and chemical properties of $\mathrm{Pt}$ nanopowder vary widely for different studies. Crystallite sizes range from 1 to $30 \mathrm{~nm} .^{22,52-56}$ Specific surface area (SSA) values of 150 to $205 \mathrm{~m}^{2} / \mathrm{g}$ have been reported for particle sizes ranging from 1 to $4.5 \mathrm{~nm} .^{22}$ Particle morphologies vary from irregular $^{22,54}$ to (pseudo)spherical. ${ }^{52,53,57}$ Increases in crystallite size have been reported when $\mathrm{Pt}$ nanopowder is subjected to temperatures of $600{ }^{\circ} \mathrm{C}$ or above. ${ }^{30,58}$

The concentration and speciation of surface oxygen on $\mathrm{Pt}$ nanopowder, as well as its dependence on particle size, remains poorly understood. ${ }^{59-62}$ Some studies have shown that surface oxygen concentration increases with decreasing particle size. ${ }^{59,60}$ Others reported that larger particle sizes correlated with higher oxygen content in the form of chemisorbed oxygen. $^{81,62}$

1.3. Impacts of Nanosized Platinum Properties on Catalytic Activity. Prior research has focused mainly on the effect of a single physical or chemical property on catalyst performance, ${ }^{60,63-69}$ such as effects of particle size on the oxygen reduction reaction, ${ }^{63}$ or facet-dependent catalytic activity on solar cell reduction reactions. ${ }^{70}$ A limitation of these and other related studies on commercial samples ${ }^{71-73}$ is that the reported property-activity relationships are restricted to only a specific set of conditions making it difficult or impossible to understand the studied processes at a mechanistic level. In addition, correlated effects of different physical, chemical, and structural properties often induce incorrect ascribing of property-activity relationships for Pt and other metal nanoparticles. ${ }^{61}$ For example, as the particle size of metal nanoparticles increases, the work function decreases, which is linked to enhanced accumulation of surface chemisorbed oxygen. ${ }^{62}$ Surface chemisorbed oxygen can also affect the catalytic activity of Pt nanoparticles. ${ }^{74-76}$

Results from previous research on nanosized platinum reveal two important and currently unresolved questions: (1) what oxygen species are present at the surfaces of nanosized platinum and in what abundance, and (2) how does surface oxygen change as a function of different synthesis conditions, sample treatments such as heating, and reaction conditions? Questions regarding surface oxygen composition are important for explaining the enigmatic variability in catalytic performance that has been reported for Pt nanocatalysts synthesized at different conditions. ${ }^{77,78}$ For example, the formation of surface oxides due to heating ${ }^{79,80}$ is known to affect the rate of reactions catalyzed by $\mathrm{Pt}^{29,81,82} \mathrm{New}$ studies and detailed characterization of commercial $\mathrm{Pt}$ nanocatalysts are thus needed to determine fundamental properties of commercial Pt nanocatalysts, as well as how they change as a function of external conditions.

This study reports detailed characterization results for commercially sourced samples of Pt black and Pt nanopowder. The two catalysts were characterized in the "as received" condition, as well as after being subjected to BET outgassing at $300{ }^{\circ} \mathrm{C}$ (Pt black-BET and Pt nanopowder-BET) and thermogravimetric analysis (TGA) in air (Pt black-TGA and Pt nanopowder-TGA). Heating was used to evaluate the effect of moderate to high temperature conditions on the initial properties of the two samples. Complementary electron microscopic imaging and small-angle X-ray scattering methods were used to quantify the crystal size, shape, and aggregation behavior of the samples. Powder X-ray and selected area electron diffraction were used to evaluate bulk atomic structural characteristics. X-ray photoelectron spectroscopy was used to quantify surface chemical composition, specifically the speciation and concentration of oxygen. Changes in particle size and surface oxygen due to heating were evaluated in terms of their impact on catalytic activity of $\mathrm{H}_{2} \mathrm{O}_{2}$ decomposition, which we have used here as a model reaction. The chemical decomposition of $\mathrm{H}_{2} \mathrm{O}_{2}$ is exothermic and is used for propulsion of miniaturized spacecraft and underwater vehicles. ${ }^{77,83,84}$ This reaction is also important in hydrogen fuel cells, where the decomposition of $\mathrm{H}_{2} \mathrm{O}_{2}$ through a nonelectrochemical pathway (without addition of electrons from the anode) lowers the energetic efficiency of the oxygen reduction reaction. Although the surface of platinum is affected by the voltage between the anode and the cathode in fuel cells, our study provides a model to understand the kinetics of the parasitic non-electrochemical decomposition of $\mathrm{H}_{2} \mathrm{O}_{2}$ in these applications. ${ }^{8-88}$

Overall, the results significantly improve our understanding of commercial $\mathrm{Pt}$ nanocatalysts by addressing key questions regarding their physical and surface chemical properties, mainly regarding the presence of oxygen, as well as how these properties change during heating.

\section{RESULTS AND DISCUSSION}

2.1. Physical Properties of Platinum Black and Platinum Nanopowder. Scanning electron microscopy (SEM) imaging showed that the as received samples of $\mathrm{Pt}$ nanopowder and $\mathrm{Pt}$ black consist of porous and irregularly shaped aggregates of nanoparticles (Figure S1). In comparison to Pt black, the aggregates of Pt nanopowder are more rounded 

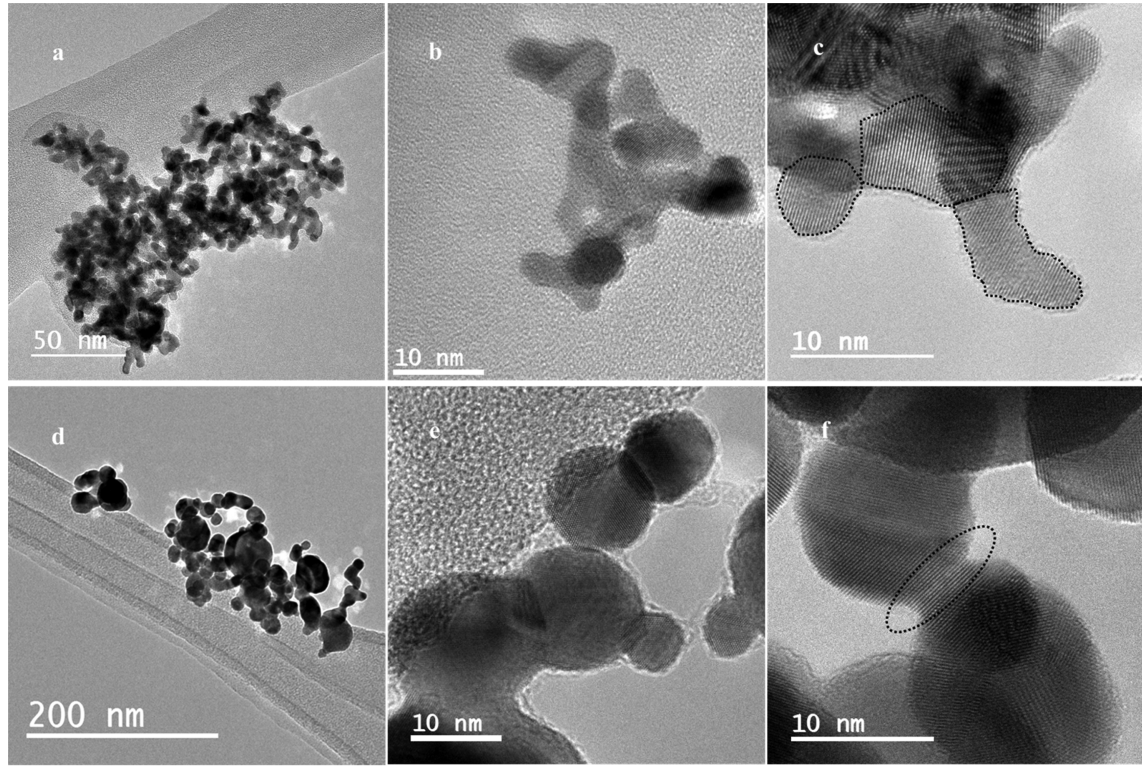

Figure 1. Electron micrograph of (a) low magnification Pt black deposited on lacey carbon grid, (b) high magnification Pt black deposited on continuous $\mathrm{Si}_{3} \mathrm{~N}_{4}$, (c) high magnification Pt black deposited on lacey carbon grid (dotted lines outline nanoparticle boundaries based on contrast), (d) low magnification Pt nanopowder deposited on lacey carbon grid, (e) high magnification Pt nanopowder deposited on lacey carbon grid, (f) high magnification of Pt nanopowder deposited on lacey carbon grid featuring fused nanocrystals (dotted line contains area where two particles are fused).

and have smoother surfaces. Sizes of aggregates determined by SEM are similar for both samples and vary from less than $1 \mu \mathrm{m}$ to approximately $50 \mu \mathrm{m}$. Individual crystallites were not discernible by SEM for either sample.

Nanoscale imaging by high-resolution transmission electron microscopy (TEM) of samples deposited on lacey carbon TEM grids showed that $\mathrm{Pt}$ nanopowder and Pt black consist of aggregates of nanosized crystallites (Figure 1). Selected area electron diffraction (SAED) patterns show continuous rings, confirming that the aggregates are polycrystalline for both samples (Figure S2). The average aggregate size of Pt black is $536 \pm 412(N=30) \mathrm{nm}$ and Pt nanopowder is $458 \pm 398 \mathrm{~nm}$ $(N=32)$. Small aggregates consisting of only a few nanocrystals were frequently observed for both samples when mounted on continuous $\mathrm{Si}_{3} \mathrm{~N}_{4}$ TEM grids.

Individual crystallites of Pt nanopowder observed by TEM were mostly pseudospherical (Figure 1d-f). Some exhibited surface facets (mostly hexagonal) while others appeared relatively smooth and featureless. In addition to individual and (loosely) aggregated nanoparticles, TEM imaging also showed fused crystallites in the case of Pt nanopowder (Figure 1f). Crystallite sizes of $\mathrm{Pt}$ nanopowder ranged mostly from 5 to $50 \mathrm{~nm}$, but larger particles up to $150 \mathrm{~nm}$ were occasionally observed. The particle size distribution was up-tailed leading to an average value of $22 \pm 19 \mathrm{~nm}$ and a median value of $16.6 \mathrm{~nm}$ (Figure 2). These particle sizes are consistent with previous reports for $\mathrm{Pt}$ nanopowder obtained by chemical vapor deposition, the same method used to synthesize the sample in this study. ${ }^{22,55}$

The majority of the Pt black crystallites were irregularly shaped (Figure 1a-c). Facets of different crystal terminations were observed on some nanocrystals but were less common than for Pt nanopowder. While most crystallites were elongated, nearly round ones were also observed (Figure 1c). The elongation did not occur systematically along any specific Miller index (data not shown). Crystallites ranged between 4

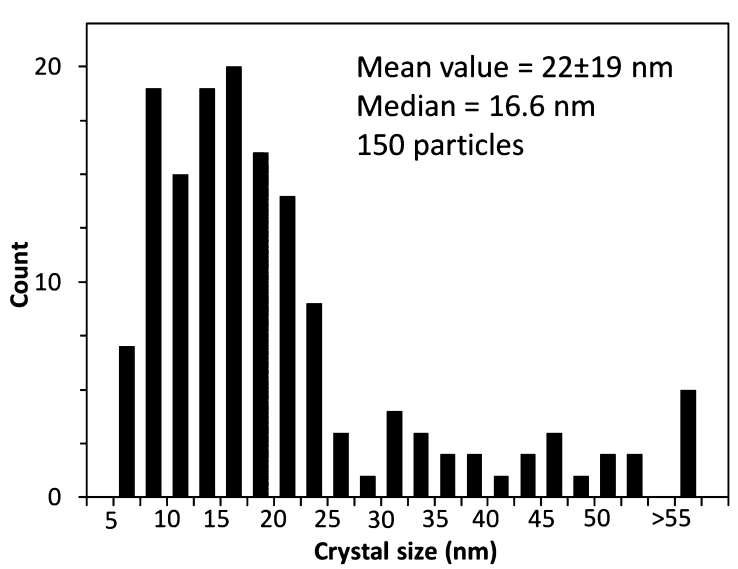

Figure 2. Nanoparticle size distribution of Pt nanopowder by TEM.

and $25 \mathrm{~nm}$ in length and between 2 and $12 \mathrm{~nm}$ in width, which is consistent with prior observations of Pt black synthesized by chemical reduction. ${ }^{28,32,36,41}$ The average length was $10 \pm 4.7$ $\mathrm{nm}$, with median value of $8.93 \mathrm{~nm}$, and the average width was $5.9 \pm 2.5$, with a median value of $5.17 \mathrm{~nm}$ (Figure 3 ). The average aspect ratio (obtained as the ratio of the longest dimension perpendicular to the widest dimension) was $1.97 \pm$ 0.75 for Pt black, $73 \%$ larger than $1.14 \pm 0.15$ obtained for $\mathrm{Pt}$ nanopowder $(p$-value $<0.001)$.

2.2. Crystal Structure, Size, and Shape of As Received and Heated Samples. Samples were subjected to two different heat treatments in order to understand the effects of moderate to high temperature on the initial properties described above. Powder X-ray diffraction (XRD) profiles for the (111) reflection of Pt black and Pt nanopowder samples are shown in Figure 4. The full XRD spectra for all samples are characteristic of FCC Pt metal ${ }^{89}$ (Figure S3). No peaks associated with $\mathrm{PtO}_{x}$ or any impurity phases were detected. Qualitative comparison shows that peak full width at half- 


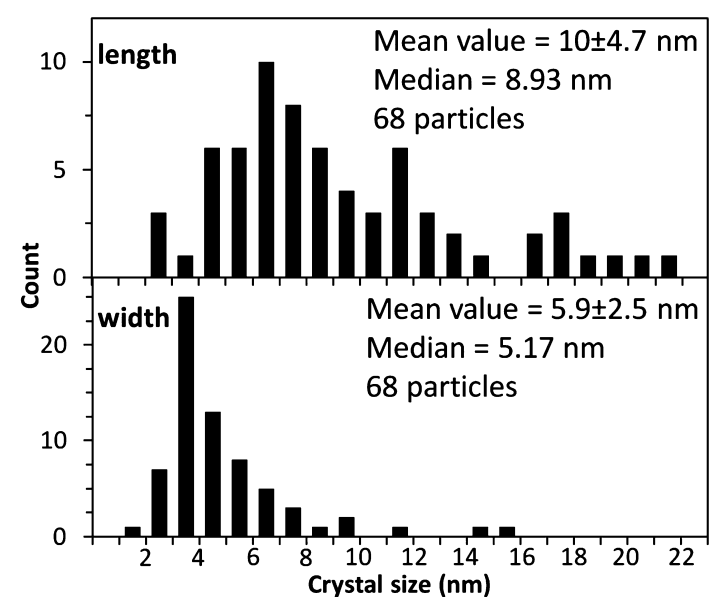

Figure 3. Crystal size (length and width) distribution of Pt black by TEM.

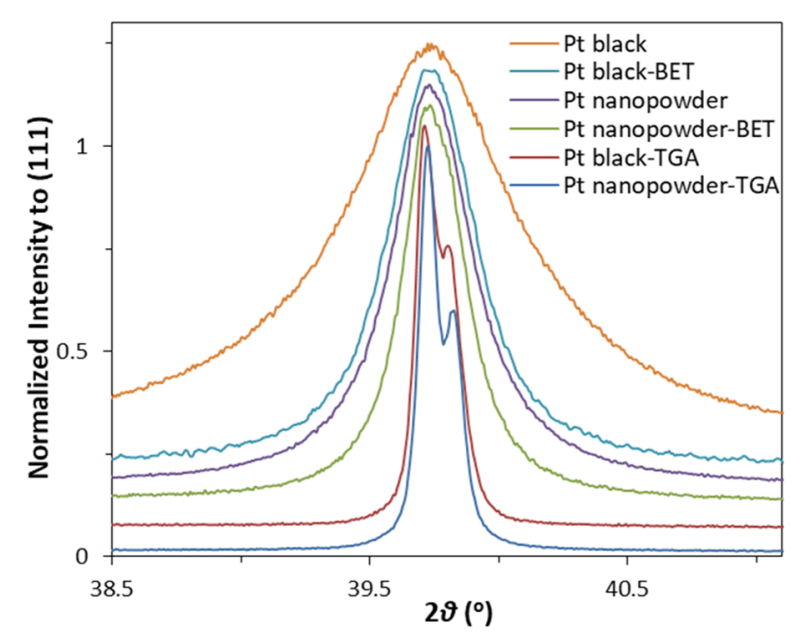

Figure 4. X-ray diffraction spectra of (111) reflection. The $y$-axis is offset in increments of 0.05 between each curve.

maximum (fwhm) is inversely related to heating temperature. This trend, combined with an absence of structural defects observable by high resolution TEM, suggests that the reduced crystallinity of $\mathrm{Pt}$ black compared to $\mathrm{Pt}$ nanopowder is primarily size-induced. ${ }^{90-93}$

Full-profile Rietveld analysis was used to determine average crystallite sizes and assess size-induced lattice strain (see Figure S4 and Table S4 for full results). The fundamental parameters approach (FPA) was used to calculate the contribution of the instrument to the XRD peak widths and confirmed using a silicon standard. Therefore, any additional peak broadening for the Pt samples was assumed to be due to the effects of crystal size and/or microstrain.

The peak profile of both as received samples was best fit with isotropic size broadening. For Pt black, TEM imaging showed that the nanocrystals are elongated in comparison to $\mathrm{Pt}$ nanopowder. Taken together this indicates that the elongation does not correspond with a specific crystallographic direction. Thus, we expect no particular crystallographic plane to be preferentially exposed at the particle surface. These results were corroborated by TEM crystallographic orientation analysis (data not shown) and suggest that the crystal size obtained through Rietveld refinement is the average for all directions. Pt nanopowder was also best fit with isotropic size- induced broadening, which also indicates no preferential crystal orientation. The average crystal size of Pt nanopowder from Rietveld was twice as large as Pt black.

Powder XRD showed a small asymmetry in the peak profiles of Pt black and Pt black-BET toward larger $d$-spacings. The asymmetry may be due to lattice strain, which would be expected for the range of particle sizes observed for Pt black and $\mathrm{Pt}$ black-BET. Previous studies of $\mathrm{Pt}$ have shown lattice contraction with decreasing size. ${ }^{76}$ This is consistent with our results as the particle size distribution is up-tailed for these samples, which causes a peak asymmetry in the XRD peak profile toward larger $d$-spacings. ${ }^{75,76}$ Including an anisotropic microstrain parameter during Rietveld analysis provided the best fit of the peak asymmetry for both Pt black and Pt blackBET. The refined values for microstrain correlated with the average particle sizes of Pt black and Pt black-BET. In contrast, the addition of a microstrain parameter did not improve the fits for Pt nanopowder and Pt nanopowder-BET. This is because little or no lattice strain would be expected for the comparatively large particle sizes of these samples.

The refined lattice dimension from Rietveld for each sample correlated well with average particle size (Figure 5 and Table

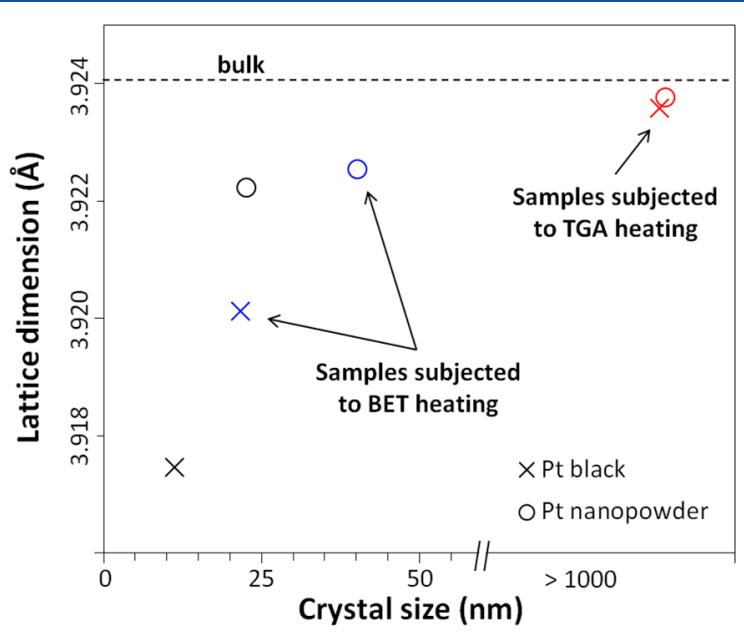

Figure 5. Effect of crystal size on lattice dimension (Rietveld analysis) of Pt black and Pt nanopowder. Samples subjected to TGA heating are separated $1 \mathrm{~nm}$ apart in the $x$-axis for graphing purposes.

S4). Pt black and Pt nanopowder samples subjected to TGA heating did not show any size-induced broadening, and thus their crystal sizes are assumed to be larger than $1 \mu \mathrm{m}$. The refined unit cell dimensions of these samples differed from the published value for the unit cell dimension of bulk Pt by $\leq 0.01 \%,{ }^{89}$ indicating that the structures of both Pt black and Pt nanopowder become relatively unstrained when subjected to TGA heating due to the increase in crystal size. Crystal growth by sintering is highly dependent on the temperature to which the nanocatalysts are subjected. ${ }^{28,36,39,46}$ For example, Páal et al. (1989) showed by TEM analysis that the particle size of Pt black increased much faster when exposed to $633 \mathrm{~K}$ compared to $473 \mathrm{~K}$ for the same amount of time. ${ }^{39}$ This result corroborates the enhanced effect of temperature (samples subjected to TGA heating) compared to exposure to lower temperatures for extended periods of time (samples subjected to BET heating) in our study.

Specific surface area (SSA) measurements were used to confirm that the increase in crystallinity during heating was due 
primarily to an increase in crystal size, rather than a decrease in the numbers of internal defects. The SSA of the as received Pt black and $\mathrm{Pt}$ nanopowder outgassed at room temperature in the BET was $35.5 \pm 0.4$ and $10.4 \pm 1.0 \mathrm{~m}^{2} \mathrm{~g}^{-1}$, respectively. Outgassing at $300{ }^{\circ} \mathrm{C}$ for $22 \mathrm{~h}$ resulted in a SSA of $11.5 \pm 0.3$ $\mathrm{m}^{2} \mathrm{~g}^{-1}$ for Pt black-BET and $5.1 \pm 0.1 \mathrm{~m}^{2} \mathrm{~g}^{-1}$ for Pt nanopowder-BET, which correspond to approximately onethird and half of the SSA of Pt black and Pt nanopowder, respectively. Heating the samples to $300{ }^{\circ} \mathrm{C}$ during BET outgassing increased the crystal size by 1.77 and 1.92 times for Pt nanopowder and Pt black (Table S4). These results suggest that the increase in crystallinity was due mainly to crystal growth since annealing defects (e.g., planar faults) would result in a negligible change in surface area.

Specific surface area determination by BET is common in characterization studies of metallic nanocatalysts, and many prior results were obtained on samples that were heated to moderate temperatures during outgassing. Our results show that heating at even moderate temperatures of $300{ }^{\circ} \mathrm{C}$, which is common in BET outgassing protocols, causes significant and detectable changes in crystallite size and specific surface area. The effect was greater for Pt black, which has a smaller average particle size than $\mathrm{Pt}$ nanopowder. This observation is consistent with numerous studies showing that decreasing size reduces the temperature and time necessary to induce material coalescence during sintering. ${ }^{23,31,38,41}$ The possible effects of heating, even if only to moderate temperatures, should be considered in past and future studies of $\mathrm{Pt}$ and other metal nanocatalysts because size and surface area have a significant impact on nanocatalyst behavior.

The accessible surface area of both $\mathrm{Pt}$ black and $\mathrm{Pt}$ nanopowder was evaluated by comparing the SSA from BET with the geometric SSA calculated using crystallites sizes determined by Rietveld analysis. Assuming monodisperse particles, the geometric SSAs of the as received Pt black and Pt nanopowder are 40.5 and $12.7 \mathrm{~m}^{2} \mathrm{~g}^{-1}$, respectively. Comparing these sizes to the measured SSAs for samples outgassed at room temperature in the BET suggests that the two nanocatalysts expose a similar fraction of their crystallite surfaces ( $81 \%$ for Pt nanopowder and $88 \%$ for Pt black). These results suggest that both nanocatalysts are partially aggregated, which was confirmed by small-angle X-ray scattering (SAXS) (Figure 6). SAXS results indicate that the average particle sizes of as received Pt black and as received $\mathrm{Pt}$ nanopowder are 18.6

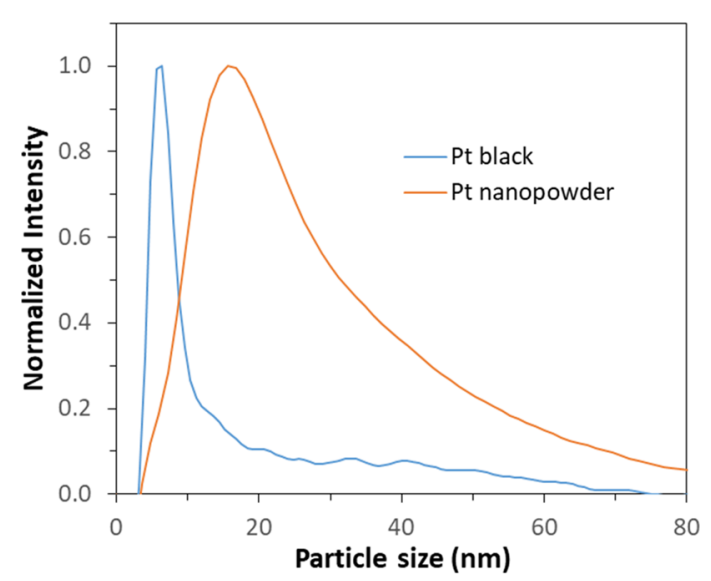

Figure 6. Volume-weighted particle size distribution of Pt nanopowder and Pt black from SAXS. and $31.4 \mathrm{~nm}$, approximately 1.5 times larger than the sizes from Rietveld analysis. The fractions of exposed surface for $\mathrm{Pt}$ black and Pt nanopowder determined in this study are significantly larger than estimates from previous studies, also comparing geometric surface area to BET surface area, which range between 20 and 50\%. ${ }^{39,46}$ This difference supports that the particle size of the samples in these previous studies may have been inadvertently affected by heating during BET outgassing.

2.3. Surface Chemical Properties. X-ray photoelectron spectroscopy (XPS) was used to evaluate the surface chemical properties of the as received samples and to compare the effects of particle size and heating. XPS analysis of the as received samples showed that the surfaces are composed only of $\mathrm{Pt}, \mathrm{C}$, and $\mathrm{O}$ (Table 1 ). The concentrations of $\mathrm{C}$ and $\mathrm{Pt}$ are

Table 1. XPS Surface Atomic Chemical Composition Analysis of Platinum Black and Platinum Nanopowder

\begin{tabular}{lccc} 
& C & O & Pt \\
Pt black & $40.4 \pm 0.9$ & $7.2 \pm 0.6$ & $52.3 \pm 0.9$ \\
Pt black-TGA & $47.6 \pm 4.1$ & $11.3 \pm 1.8$ & $41.1 \pm 3.1$ \\
Pt nanopowder & $40.4 \pm 1.9$ & $12.3 \pm 1.4$ & $47.2 \pm 3.2$ \\
Pt nanopowder-TGA & $53.3 \pm 5.6$ & $14.5 \pm 0.8$ & $32.1 \pm 6.0$ \\
\hline
\end{tabular}

not statistically different between Pt black and Pt nanopowder ( $p$-value $=0.99$ and $p$-value $=0.10$, respectively $)$. In comparison, surface oxygen is 1.7 times higher on $\mathrm{Pt}$ nanopowder $(p$-value $=0.01)$, which has a larger average particle size than Pt black (Table S4).

High resolution XPS analysis of the $\mathrm{O} 1 \mathrm{~s}$ peak was performed to evaluate the chemical speciation of oxygen present at the surface of both Pt black and Pt nanopowder (Figure S5). In addition to having enhanced surface oxygen content, high resolution XPS analysis of the $\mathrm{O}$ 1s peak showed that the fraction of oxygen chemisorbed to $\mathrm{Pt}$ (O3 component) is 1.5 times higher for Pt nanopowder than for Pt black $(p$-value $=0.03)$. The fraction of oxygen bonded to carbon $(\mathrm{O} 1+\mathrm{O} 2$ component) is similar for both nanocatalysts $(p$-value $=0.37)($ Table 2$)$.

\section{Table 2. High Resolution XPS O 1s Peak Area Analysis}

\begin{tabular}{lccc} 
& $\mathrm{O} 1+\mathrm{O} 2$ & $\mathrm{O} 3$ & $\mathrm{O} 4$ \\
Pt black & $81.1 \pm 7.7$ & $16.1 \pm 3.2$ & $2.8 \pm 3.0$ \\
Pt black-TGA & $31.3 \pm 5.0$ & $67.1 \pm 5.4$ & $1.6 \pm 2.7$ \\
Pt nanopowder & $75.9 \pm 2.4$ & $23.8 \pm 2.1$ & $0 \pm 0$ \\
Pt nanopowder-TGA & $58.1 \pm 11$ & $40.2 \pm 7.5$ & $1.7 \pm 1.5$ \\
\hline
\end{tabular}

The accumulation and speciation of oxygen on Pt surfaces has been a focus of debate in the literature due to its only partly understood relation to particle size ${ }^{59-62}$ and effect on oxidation-reduction reactions. ${ }^{81,94,95}$ The present study shows that larger particle size corresponds with higher surface oxygen content and enhanced fraction of chemisorbed oxygen. This is consistent with results from previous studies also showing that the accumulation of chemisorbed oxygen is enhanced on larger Pt particles, compared to smaller ones. ${ }^{61,62}$ The effect was attributed to larger particles having a lower work function, which favors the chemisorption of oxygen onto the surface. ${ }^{61,62}$ As opposed to oxygen chemisorbed to the surface of $\mathrm{Pt}$, the amounts of oxygen chemically bonded to $\mathrm{Pt}\left(\mathrm{PtO}_{x}\right)$ were 
Table 3. Rate Constant and Activation Energy of $\mathrm{H}_{2} \mathrm{O}_{2}$ Decomposition by Platinum Nanocatalysts

\begin{tabular}{|c|c|c|c|c|}
\hline sample & $(\mathrm{O} / \mathrm{Pt})_{\mathrm{s}}$ & $d, \mathrm{~nm}$ & $E_{\mathrm{a}}, \mathrm{kJ} \mathrm{\textrm {mol } ^ { - 1 }}$ & $K, \mathrm{~mol} \mathrm{~m}^{-2} \mathrm{~s}^{-1}$ \\
\hline Pt black & $0.20 \pm 0.01$ & $9.38 \pm 0.1$ & $33 \pm 3$ & $(3.3 \pm 0.7) \times 10^{-3}$ \\
\hline Pt black-BET & $0.21 \pm 0.03$ & $18.7 \pm 0.1$ & $34 \pm 5$ & $(5.1 \pm 1.6) \times 10^{-3}$ \\
\hline Pt black-air 240 & $0.24 \pm 0.07$ & $10.2 \pm 0.9$ & $29 \pm 4$ & $(7.9 \pm 1.4) \times 10^{-3}$ \\
\hline Pt black-air ${ }_{300}$ & $0.26 \pm 0.02$ & $9.2 \pm 0.1$ & $32 \pm 4$ & $(1.1 \pm 0.2) \times 10^{-2}$ \\
\hline Pt nanopowder & $0.32 \pm 0.02$ & $21.7 \pm 0.1$ & $26 \pm 3$ & $(3.5 \pm 0.7) \times 10^{-2}$ \\
\hline Pt nanopowder-BET & $0.31 \pm 0.04$ & $30.2 \pm 1.4$ & $21 \pm 8$ & $(4.2 \pm 1.2) \times 10^{-2}$ \\
\hline Pt-nanopowder-air 240 & $0.30 \pm 0.04$ & $21.3 \pm 0.7$ & $20 \pm 8$ & $(3.9 \pm 2.1) \times 10^{-2}$ \\
\hline Pt-nanopowder-air 300 & $0.30 \pm 0.03$ & $22.2 \pm 0.1$ & $26 \pm 3$ & $(3.3 \pm 3.6) \times 10^{-2}$ \\
\hline
\end{tabular}

negligible for both Pt black and Pt nanopowder, i.e., within the measurement error (O4 component).

Surface chemical analysis of the samples subjected to TGA heating suggest that particle size is not the only factor that explains why surface chemisorbed oxygen is enhanced on $\mathrm{Pt}$ nanopowder compared to Pt black. Heating the samples to 700 ${ }^{\circ} \mathrm{C}$ during TGA in air caused an increase in surface oxygen content of 1.56 times for Pt black $(p$-value $=0.047)$. The surface oxygen content of Pt-nanopowder increased 1.18 times, but the difference was not statistically significant ( $p$-value $=$ 0.089 ), presumably because the surface oxygen content of as received Pt nanopowder was already enhanced. The increase in surface oxygen concentration for Pt black correlated with a 4.1 times increase in the fraction of chemisorbed oxygen, $\mathrm{Pt}(\mathrm{O})$ $(p$-value $<0.001)$. For Pt nanopowder, heating resulted in a 1.7 times increase in the fraction of $\operatorname{Pt}(\mathrm{O})(p$-value $=0.05)$. An increase in the amount of surface $\mathrm{Pt}(\mathrm{O})$ for heated samples has been observed in previous studies. Ono et al. (2011) found that $10-20 \%$ surface oxygen was present on $\mathrm{Pt}$ nanoparticles exposed to temperatures of $430{ }^{\circ} \mathrm{C}$ in air. ${ }^{79}$

The presence of $\operatorname{Pt}(\mathrm{O})$ at the surfaces of the as received samples may be related in part to synthesis conditions. $\mathrm{Pt}$ nanopowder is synthesized by chemical vapor deposition, which involves temperatures of $700-800{ }^{\circ} \mathrm{C}$. Temperatures in this range are known to promote the incorporation of oxygen in the form of $\mathrm{Pt}(\mathrm{O}){ }^{79}$ In contrast, synthesis of Pt black is done by chemical reduction of chloroplatinic acid to metallic $\mathrm{Pt}$ at room temperature. Based on our results, this produces a more chemically reduced (i.e., less $\mathrm{Pt}(\mathrm{O})$ ) surface than $\mathrm{Pt}$ nanopowder. Our surface chemical analysis of the TGA heated samples is consistent with this hypothesis.

XPS also indicates the presence of carbon-bearing compounds at the surfaces of both nanocatalysts (Figure S5). This is consistent with TEM observations showing the presence of a thin and irregular coating layer on the particle surfaces of both nanocatalysts (Figure 1). The average thicknesses of the coatings are $1.8 \pm 0.7$ and $1.3 \pm 0.7 \mathrm{~nm}$ for Pt black and Pt nanopowder, respectively. The $\mathrm{C}$ 1s peaks obtained for both Pt black and Pt nanopowder are characteristic of adventitious carbon. ${ }^{96-100}$ The fraction of carbon bonded to oxygen became almost negligible when Pt black and Pt nanopowder were subjected to TGA heating $(\mathrm{C} 2+\mathrm{C} 3$ components). This was accompanied by an increase in the fraction of carbon bonded to carbon or to hydrogen ( $\mathrm{C} 1$ component). These spectra are characteristic of graphitic-like compounds, which is consistent with the conversion of aliphatic chains (adventitious carbon) into a graphitic carbon due to the materials being subjected to temperatures above $450{ }^{\circ} \mathrm{C}$, in a process known as coke formation. ${ }^{101-108}$

2.4. Impact of Catalyst Properties on Catalytic Activity. Our characterization results showed that heating affects both particle size and abundance of chemisorbed oxygen at the surface of $\mathrm{Pt}$ nanocatalysts. This is important because particle size and surface chemistry directly affect the catalytic activity of $\mathrm{Pt}$ nanoparticles in a variety of chemical reactions, such as (de)hydrogenation reactions, ${ }^{109}$ carbon monoxide oxidation, ${ }^{110}$ oxygen reduction reaction, ${ }^{59,60,111,112}$ and decomposition of $\mathrm{H}_{2} \mathrm{O}_{2}{ }^{29,81,82,113}$ Changes in particle size affect the position and shape of the valence band and consequently the surface work function. ${ }^{114}$ Larger Pt nanoparticles exhibit lower work function values, which correlate with a lower oxidation potential and confer greater capacity to provide electron density to the reagents. ${ }^{115,116}$ Heating Pt in the presence of oxygen promotes dissociative oxygen chemisorption onto its surface and decomposition of surface $\mathrm{PtO}_{x}$ species. ${ }^{79,117}$ This is important for the present study because weakly interacting surface oxygen species have been linked to enhanced activity in chemical reactions that involve transference of oxygen atoms. ${ }^{74,111,118}$

The overall effect of particle size and surface oxides in the reaction kinetics depends on the reaction mechanism and conditions of reaction. ${ }^{29,81,82,88}$ To understand the interplay of average particle size $(d)$ and surface atomic oxygen to platinum ratio, $(\mathrm{O} / \mathrm{Pt})_{s}$, in catalytic activity, we compared the rate constant $(\mathrm{K})$ of $\mathrm{H}_{2} \mathrm{O}_{2}$ decomposition by $\mathrm{Pt}$ black and $\mathrm{Pt}$ nanopowder in the as supplied condition to that of samples heated at $300{ }^{\circ} \mathrm{C}$ for $22 \mathrm{~h}$ in vacuum during BET outgassing (Pt black-BET and Pt-nanopowder-BET), samples heated at $300{ }^{\circ} \mathrm{C}$ for $22 \mathrm{~h}$ in air (Pt black-air ${ }_{300}$ and Pt nanopowderair $_{300}$ ), and samples heated at $240{ }^{\circ} \mathrm{C}$ for $24 \mathrm{~h}$ in air (Pt blackair $_{240}$ and Pt nanopowder-air 240 ) (Table 3).

Results show that the catalytic activity of Pt black correlates with the surface $\mathrm{O} / \mathrm{Pt}$ ratio. The catalytic activity of Pt black increased 3 times $(p$-value $<0.01)$ when the sample was heated in air, which corresponded with a 1.3 times increase in $\mathrm{O} / \mathrm{Pt}$. In comparison, the catalytic activity of $\mathrm{Pt}$ black heated in vacuum (absence of oxygen) only increased 1.5 times (90\% confidence level, $p$-value $=0.10)$. Since the surface oxygen concentration of Pt black and Pt black-BET are similar, we attribute this increase in catalytic activity to the larger particle size. In contrast, the rate constants of Pt nanopowder-BET and Pt-nanopowder heated in air (both at 240 and $300{ }^{\circ} \mathrm{C}$ ) were similar to Pt nanopowder in the as received condition ( $p$-value $=0.89, p$-value $=0.70$, and $p$-value $=0.83$, respectively). The similar rate constants obtained for all Pt nanopowder samples are consistent with the fact that these samples also have a similar surface $\mathrm{O} / \mathrm{Pt}$ ratio. Overall, the results indicate catalytic activity increases with increasing particle size and surface oxygen abundance. We performed multivariate analysis of the rate constant of the eight catalyst samples as a function of $\mathrm{O} /$ Pt ratio and particle size to evaluate the contribution of each variable to the catalytic activity. 
Figure 7 shows that the catalytic activity of Pt black and Pt nanopowder is well described by the combined effect of

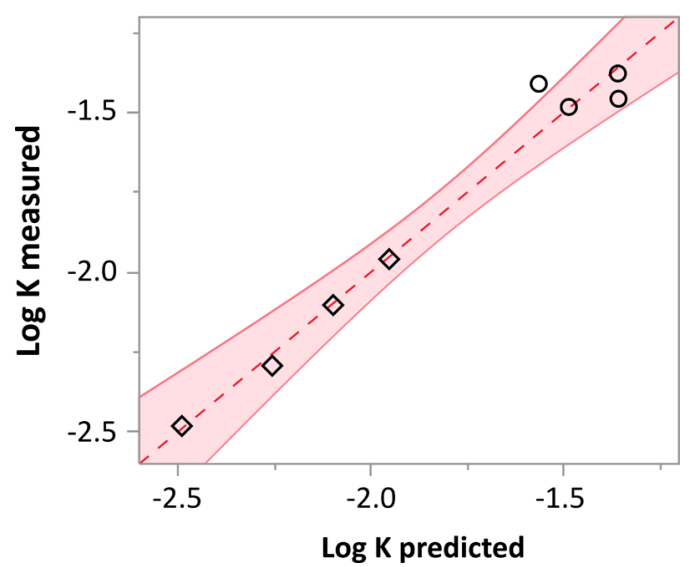

Figure 7. Effect of $\mathrm{O} / \mathrm{Pt}$ ratio and particle size in the rate constant $(K)$ of Pt black $(\diamond)$ and Pt nanopowder $(\bigcirc)$ samples.

particle size and $\mathrm{O} / \mathrm{Pt}$ ratio. All eight catalyst samples fall along one regression line with $R^{2}=0.97$ which suggests that particle size and $\mathrm{O} / \mathrm{Pt}$ ratio explain the majority of variance of the rate constant within the range of studied conditions. The rate constant of $\mathrm{H}_{2} \mathrm{O}_{2}$ decomposition as a function of particle size and $\mathrm{O} / \mathrm{Pt}$ ratio on these $\mathrm{Pt}$ black and $\mathrm{Pt}$ nanopowder samples is given by

$$
K=10^{0.4 \pm 0.5}\left(d^{0.45 \pm 0.23}\right)(\mathrm{O} / \mathrm{Pt})_{\mathrm{s}}^{4.76 \pm 0.58}
$$

From this it is clear that surface $\mathrm{O} / \mathrm{Pt}$ ratio has a stronger effect than particle size on the catalytic activity of platinum in the decomposition of $\mathrm{H}_{2} \mathrm{O}_{2}$.

These results for Pt black and $\mathrm{Pt}$ nanopowder emphasize the importance of surface chemisorbed oxygen in the rate of $\mathrm{H}_{2} \mathrm{O}_{2}$ decomposition. Relatively weak interactions between $\mathrm{Pt}$ and $\mathrm{O}$ in chemisorbed oxygen (i.e., $\mathrm{Pt}(\mathrm{O})$ ) can easily be reduced and reoxidized. ${ }^{119}$ In comparison, the stronger $\mathrm{Pt}-\mathrm{O}$ bonds for $\mathrm{PtO}_{x}$ species would require larger energy to break, which is not possible given the chemical potentials of the reagents in many reactions. $^{63,82}$ It is worthy to note that the correlation between surface chemisorbed oxygen and catalytic activity has also been ascribed to a contraction of the surface atomic layer of $\mathrm{Pt}$ induced by oxygenated species, resulting in a downshift of the d-band center position. ${ }^{74}$ The effect of particle size is explained by the fact that larger metallic nanoparticles exhibit a smaller oxidation potential, which causes more oxygen from $\mathrm{H}_{2} \mathrm{O}_{2}$ to react with $\mathrm{Pt}$ to form $\mathrm{Pt}(\mathrm{O}) .{ }^{115,116,118,120}$ This is consistent with the correlation between lattice strain and activation energy of oxygen chemisorption on various Pt alloys, which again has been attributed to particle size effects on the d-band position of the surface $\mathrm{Pt}$ atoms. ${ }^{121,122}$

We attribute the 10 times higher catalytic activity of $\mathrm{Pt}$ nanopowder compared to Pt black, as result of its 2 times larger particle size and 1.5 times higher surface chemisorbed oxygen abundance. However, it is possible that other factors may contribute to the relatively lower catalytic activity of $\mathrm{Pt}$ black. For example, trace amounts of $\mathrm{PtO}_{x}$ in the $\mathrm{Pt}$ black structure due to incomplete reduction of its precursor (Adam's catalyst, $\mathrm{PtO}_{2}$ ) may result in a fraction of the catalyst surface that is unreactive toward $\mathrm{H}_{2} \mathrm{O}_{2}$. Another possibility is that the smaller average particle size of $\mathrm{Pt}$ black results in a higher fraction of edges and corners, which are sites characterized by different steric and electronic properties compared to terrace surfaces. ${ }^{60,79} \mathrm{Pt}$ atoms at edges and/or corners can establish stronger bonds with oxygen and/or hydroxyl species, which require more energy to be displaced. ${ }^{123}$ As a result, $\mathrm{Pt}$ nanopowder more easily establishes metastatic interactions with oxidizing reactants, which is associated with enhanced catalytic properties. $^{115}$

In this study, a suite of complementary analytical characterization methods were used to quantify fundamental physical and chemical characteristics of two common types of commercial Pt nanocatalysts. Correlations were drawn between changes in particle size and surface chemistry, in particular the abundance of chemisorbed $\mathrm{Pt}(\mathrm{O})$. The availability of this information makes it possible to assess and interpret differences in the catalytic activity of these two materials, as demonstrated here by evaluating the effects of particle size and surface chemical composition on the rate of $\mathrm{H}_{2} \mathrm{O}_{2}$ decomposition. Developing a deeper and more predictive understanding of property-activity relationships in these and other nanocatalysts will improve the efficiency of existing catalysts and the design of future catalyst materials. This will have benefits in many industrial and technological applications, such as petroleum cracking, catalytic conversion in modern automobiles, hydrogen peroxide sensors, and hydrogen fuel cells. ${ }^{21,25,28,37,124}$

\section{CONCLUSIONS}

This study measured and compared the atomic structural, physical, and chemical properties of two commercial platinum nanocatalysts both as received and after exposure to two common heating protocols used as part of standard characterization. Smaller average particle sizes corresponded with increased lattice strain and a lower abundance of surface oxygen. Oxygen associated directly with platinum at the surface of these nanocatalysts is in the form of chemisorbed oxygen, and no significant amounts of chemically bonded oxygen (i.e., $\mathrm{PtO}_{x}$ ) were found. The concentration of chemisorbed oxygen increases with increasing particle size, as well as due to heating of the nanoparticles in the presence of oxygen (air). Samples with smaller average particle sizes are more susceptible to the effect of heat both in terms of crystal growth and increased surface oxygen. Average particle size and surface composition directly affected the surface electronic properties of metallic nanoparticles and consequently their catalytic behavior, which was evaluated here in terms of $\mathrm{H}_{2} \mathrm{O}_{2}$ decomposition. Our results show that larger average particle size and higher surface chemisorbed oxygen abundance both correlated with enhanced activity toward the decomposition of $\mathrm{H}_{2} \mathrm{O}_{2}$.

In summary, this study highlights the inherent variability of commercial platinum nanocatalysts, particularly in terms of average particle size and surface oxygen abundance. The results also show how those differences affect their susceptibility to external conditions, such as mild heat exposure during, for example, BET outgassing. Surface oxygen plays an important role in oxidation-reduction reactions catalyzed by platinum nanocatalysts, such as $\mathrm{H}_{2} \mathrm{O}_{2}$ decomposition, which we used here as a model reaction to quantify and compare catalytic activity. These results are important for the development of more robust property-activity relationships of $\mathrm{Pt}$ and other metal nanocatalysts. 


\section{MATERIALS AND METHODS}

4.1. Samples. Pt nanopowder and Pt black were obtained from Sigma-Aldrich (St. Louis, MO, USA). According to the manufacturer, Pt nanopowder was synthesized by combustion chemical vapor condensation and its (TEM) particle size is $<50 \mathrm{~nm}$. Pt black was derived from chemical reduction of $\mathrm{H}_{2} \mathrm{PtCl}_{6}$ to metallic $\mathrm{Pt}^{25,26}$ and its reported average aggregate size is $\leq 20 \mu \mathrm{m}$. Pt black and Pt nanopowder were received as finely divided dry powders with colors ranging from dark gray to black. Samples were characterized in four different conditions: (1) "as received" from the supplier (Pt black and Pt nanopowder), (2) heated in air at $240{ }^{\circ} \mathrm{C}$ for $24 \mathrm{~h}$, (3) subjected to heat in vacuum conditions at $300{ }^{\circ} \mathrm{C}$ for $22 \mathrm{~h}$ during BET outgassing (Pt black-BET and Pt nanopowder-BET), and (4) subjected to TGA heating conditions in air from room temperature to $700{ }^{\circ} \mathrm{C}$ at a heating rate of $10^{\circ} \mathrm{C} / \mathrm{min}$ (Pt black-TGA and Pt nanopowder-TGA).

4.2. Microscale Physical and Chemical Characterization by SEM. Scanning electron microscopy analysis was performed on dry powder samples loaded on double sided carbon conductive tape (Ted Pella, USA). Images were collected using a FEI Quanta 600 FEG operated at an accelerating voltage of $20 \mathrm{kV}$.

4.3. Bulk Crystal Structure and Volume-Weighted Particle Size by X-ray Diffraction and Small-Angle X-ray Scattering. Powder X-ray diffraction and small-angle X-ray scattering data were collected using a Panalytical Empyrean Nano Edition multipurpose diffractometer equipped with a $\mathrm{Cu}$ source $\left(\lambda_{\mathrm{Cu} \alpha}=0.15406 \mathrm{~nm}\right)$ and Bragg-Brentano HD divergent beam optic with an energy resolution of about $450 \mathrm{eV}$. Dry samples of Pt nanopowder and Pt black for powder XRD were loaded individually onto a $32 \mathrm{~mm}$ diameter, low background Si wafer sample holder with a $0.2 \mathrm{~mm}$ well (Panalytical). Diffracted intensities from the samples were collected from 20 to $130^{\circ}$ $2 \theta$ in approximately $0.007^{\circ}$ increments using a GaliPIX ${ }^{3 \mathrm{D}}$ area detector system and exposure time of approximately $188 \mathrm{~s} /$ point. The raw scattering data were processed in HighScore (Panalytical). Average crystal sizes for each sample were estimated using a full profile Rietveld analysis. SAXS measurements were made using a $\mathrm{Cu}$ focusing mirror and $1 / 32^{\circ}$ fixed diffraction slit. Dry samples were flat mounted between Scotch tape and Mylar film and measured in a Scatter $\mathrm{X}^{78}$ evacuated sample holder and beam path. Data processing and volume-weighted size distribution $\left(D_{\mathrm{v}}(R)\right)$ analysis were performed using EasySAXS (Panalytical).

4.4. Rietveld Analysis. Rietveld analysis of powder XRD data was performed using Profex 3.20.2. ${ }^{125}$ A fundamental parameters approach (FPA) was used to calculate the instrumental weight function from the device configuration. A silicon NIST640d standard for line position and line shape was used to verify the instrumental weight function.

The initial unit cell parameter $(a)$ and isotropic displacement parameters, and spacegroup $F m \overline{3} m$ (No. 225) with Wyckoff value $4 a$ for face-centered cubic (FCC) platinum were obtained from crystallographic information file (CIF) no. 0011157 obtained from the AMCSD. ${ }^{89}$ A pseudo-Voigt function (RP4) and spherical harmonics correction (SPHAR4) were used in all fits to model peak profiles. The displacement parameter for Pt was left fixed at the initial value $(U=0.001)$. Two fitting strategies were tested to account for peak broadening and asymmetry. One strategy included fitting the data with two separate Pt phases having the same FCC structure. The unit cell dimension and peak profile parameters for size-induced broadening of the Lorentzian (B1) and Gaussian (k1) components were allowed to vary independently for each phase. The second strategy used a single Pt phase affected by size-induced broadening (B1) and anisotropic microstrain (k2). The unit cell dimension and $\mathrm{B} 1$ were first allowed to vary freely, and then $\mathrm{k} 2$ was added to the refinement. Further details regarding the fitting strategy for each sample are included in Results and Discussion.

4.5. Specific Surface Area by BET. The gas accessible surface areas of Pt black and $\mathrm{Pt}$ nanopowder were determined by BET analysis with a Quantachrome Autosorb-1 using a $6 \mathrm{~mm}$ borosilicate sample cell and nitrogen as adsorbate. Two protocols for outgassing the samples at room temperature $\left(23{ }^{\circ} \mathrm{C}\right)$ or $300{ }^{\circ} \mathrm{C}$ were used to evaluate the effects of heating on surface area. Samples outgassed at
$300{ }^{\circ} \mathrm{C}$ were recovered for XRD analysis (Pt black-BET and $\mathrm{Pt}$ nanopowder-BET). Samples were analyzed in triplicate and outgassed for $22 \mathrm{~h}$ followed by standard 11-point BET analysis in the $P / P_{0}$ range of $0.05-0.35$. Sample weight was obtained by subtracting the weight of the empty sample holder from that of the sample holder plus outgassed sample for each run. Weight determinations were obtained from the average of five consecutive measurements, and SSA values were obtained from the analysis of three independent samples of each catalyst.

4.6. Surface Composition by XPS. X-ray photoelectron spectroscopy quantitative surface chemical characterization of the samples was done using a PHI Quantera SXM scanning photoelectron spectrometer microprobe. Samples were deposited on double coated carbon conductive tape (Ted Pella, USA). High energy resolution XPS data were collected for selected $\mathrm{Pt}, \mathrm{O}$, and $\mathrm{C}$ peaks with $0.1 \mathrm{eV}$ of energy resolution at a pressure of $10^{-7} \mathrm{~Pa}$. High resolution XPS was done on the $\mathrm{C} 1 \mathrm{~s}, \mathrm{O} 1 \mathrm{~s}$, and $\mathrm{Pt} 4 \mathrm{f}$ peaks. The raw spectroscopy data were processed using Phi Multipak software. High resolution XPS analysis with peak deconvolution and charge calibration was performed using CASA XPS. Charging was referenced to the C1 component of adventitious $\mathrm{C} 1 \mathrm{~s}$ peak at a binding energy of $284.8 \mathrm{eV}$ for all samples. The $\mathrm{O}$ 1s spectra were deconvoluted into four components for all samples (Figure S5). Components 1 and 2 relate to oxygen present in adventitious carbon, attributed as follows: O1 $(532.6 \mathrm{eV},-\mathrm{C}=\mathrm{O}$ and $\mathrm{C}-\mathrm{OH}) ; \mathrm{O} 2(533.9 \mathrm{eV},-\mathrm{COOH}$ structure). ${ }^{126}$ Components 3 and 4 reflect oxygen bonded to Pt in the form of $\mathrm{Pt}(\mathrm{O})$ - chemisorbed oxygen - at $531.60 \mathrm{eV}^{126,127}$ and in the form of $\mathrm{PtO}_{x}$ at $530.30 \mathrm{eV}$, respectively. ${ }^{1.7,128}$ The $\mathrm{C} 1 \mathrm{~s}$ peak was deconvoluted into three symmetric components for Pt black and $\mathrm{Pt}$ nanopowder, attributed as follows: $\mathrm{C} 1(284.8 \mathrm{eV}, \mathrm{C}-\mathrm{C}, \mathrm{C}-\mathrm{H}$ bonds), $\mathrm{C} 2$ (286.3 eV, C-O-C, $\mathrm{C}-\mathrm{O}-\mathrm{H}$ bonds), $\mathrm{C} 3(288.6 \mathrm{eV}$, $\mathrm{C}=\mathrm{O}, \mathrm{O}-\mathrm{C}=\mathrm{O}$ bonds). Two extra components $\mathrm{C} 5(284.4 \mathrm{eV}, \mathrm{C}=$ C structure) with its respective $\pi-\pi^{*}$ shakeup C6 at $290.79 \mathrm{eV}$ were added for the fits to samples subjected to TGA heating to account for the presence of graphitic-like bonds. ${ }^{126}$ The $\mathrm{C} 1$ component was used as a charging reference at a binding energy of $284.8 \mathrm{eV}$ for all samples.

4.7. Thermogravimetric Analysis. Thermogravimetric analysis was performed in a TA Instruments Q5000 equipped with $100 \mu \mathrm{L}$ capacity titanium pans. Samples were analyzed in triplicate (approximately $15 \mathrm{mg}$ each) in air. The protocol included a $20 \mathrm{~min}$ isotherm at $90{ }^{\circ} \mathrm{C}$ to minimize the weight loss associated with physisorbed water. Samples were then heated from 90 to $700{ }^{\circ} \mathrm{C}$ at 10 ${ }^{\circ} \mathrm{C} / \mathrm{min}$. TGA samples were recovered for XPS and XRD analysis (Pt black-TGA and Pt nanopowder-TGA).

4.8. Transmission Electron Microscopy and Selected Area Electron Diffraction. Transmission electron microscopy was performed on a JEOL 2100 equipped with a high resolution pole piece and a thermionic emission gun operated at $200 \mathrm{kV}$. Point-topoint resolution of this TEM is $0.23 \mathrm{~nm}$. Samples were prepared by dispersing approximately $2 \mathrm{mg}$ of dry sample in $2 \mathrm{~mL}$ of methanol (Fisher Scientific, USA), followed by a $2 \mathrm{~min}$ sonication. The dispersion was then filtered through a $0.22 \mu \mathrm{m}$ pore size filter, and $10-20 \mu \mathrm{L}$ of filtrate was loaded onto a lacey carbon support film on a copper grid mesh (Ted Pella, USA) or a continuous film of amorphous $\mathrm{Si}_{3} \mathrm{~N}_{4}$ on a silicon frame (Ted Pella, USA). SAED patterns were obtained at camera lengths of $80-150 \mathrm{~mm}$ and exposure times of 20-40 s. Gatan Digital Micrograph software was used for image processing and analysis. Diffraction patterns were analyzed with the Circular Hough Transform diffraction analysis script, an add-on to Gatan Digital Micrograph software developed by David Mitchell (2007). ${ }^{129}$ Reciprocal space distances were obtained with the rotational average of diffraction spots obtained from polycrystalline samples, improving the statistical significance and reducing the error associated with these measurements.

4.9. Derivation of Rate Constants. Rate constants of $\mathrm{H}_{2} \mathrm{O}_{2}$ decomposition were determined at $22{ }^{\circ} \mathrm{C}$ by multivariate linear regression analysis of the rate of $\mathrm{H}_{2} \mathrm{O}_{2}$ decomposition as a function of $\mathrm{C}_{\mathrm{H}_{2} \mathrm{O}_{2}}, a_{\mathrm{H}}^{+}$(activity of $\mathrm{H}^{+}$) and $1 / \mathrm{T}$ for each catalyst sample. Rate measurements were performed following the protocol described in ref 130 for Pt black-BET (six data), Pt black-air ${ }_{300}$ (eight data), Pt 
nanopowder-BET (four data), and Pt nanopowder-air ${ }_{300}$ (six data). The measured rates for each set of reaction conditions can be found in Table S6. The rate constants of Pt black and Pt nanopowder in the as received condition, Pt black-air ${ }_{240}$, and Pt nanopowder-air ${ }_{240}$ were calculated from rate measurements reported in ref 130 for these four catalyst samples.

\section{ASSOCIATED CONTENT}

\section{S Supporting Information}

The Supporting Information is available free of charge on the ACS Publications website at DOI: 10.1021/acsaem.8b00474.

Results from previous studies characterizing Pt black and Pt nanopowders; SEM images of dry nanopowders; SAED patterns of nanopowders; compilation of average $d$-spacing values; XRD profiles; Rietveld analysis results; full profile Rietveld fits; high-resolution XPS analyses; high-resolution Pt 4f7/2 peak area and peak position analysis; TGA curves; raw data of rate measurements (PDF)

\section{AUTHOR INFORMATION}

\section{Corresponding Author}

*E-mail: mfrede2@vt.edu.

\section{ORCID}

Rui Serra-Maia: 0000-0003-4576-7662

F. Marc Michel: 0000-0003-2817-980X

\section{Notes}

The authors declare no competing financial interest.

\section{ACKNOWLEDGMENTS}

F.M.M. and R.S.-M. gratefully acknowledge financial support from the Virginia Tech Institute for Critical Technology and Applied Science (ICTAS) through a Junior Faculty Collaborative Grant (Grant ICTAS-JFC 175884). R.S.-M. gratefully acknowledges the Virginia Tech College of Science Roundtable Alumni Advisory Group for financial support provided through a "Make-a-Difference" Scholarship, as well as the Department of Geosciences for support provided by Sir Aubrey and Madam Eula Orange Scholarship funds. We also thank Dr. Robert Bodnar and Mr. Charles Farley for support with selected experiments.

\section{REFERENCES}

(1) Wieckowski, A.; Savinova, E. R.; Vayenas, C. G. Catalysis and electrocatalysis at nanoparticle surfaces; CRC Press: New York, 2003.

(2) Narayanan, R.; El-Sayed, M. A. Effect of Colloidal Nanocatalysis on the Metallic Nanoparticle Shape: The Suzuki Reaction. Langmuir 2005, 21, 2027-2033.

(3) Wilson, O. M.; Knecht, M. R.; Garcia-Martinez, J. C.; Crooks, R. M. Effect of Pd Nanoparticle Size on the Catalytic Hydrogenation of Allyl Alcohol. J. Am. Chem. Soc. 2006, 128, 4510-4511.

(4) Dejhosseini, M.; Aida, T.; Watanabe, M.; Takami, S.; Hojo, D.; Aoki, N.; Arita, T.; Kishita, A.; Adschiri, T. Catalytic cracking reaction of heavy oil in the presence of cerium oxide nanoparticles in supercritical water. Energy Fuels 2013, 27, 4624-4631.

(5) Alkhaldi, S.; Husein, M. M. Hydrocracking of heavy oil by means of in situ prepared ultradispersed nickel nanocatalyst. Energy Fuels 2014, 28, 643-649.

(6) Popczun, E. J.; McKone, J. R.; Read, C. G.; Biacchi, A. J.; Wiltrout, A. M.; Lewis, N. S.; Schaak, R. E. Nanostructured Nickel Phosphide as an Electrocatalyst for the Hydrogen Evolution Reaction. J. Am. Chem. Soc. 2013, 135, 9267-9270.

(7) Popczun, E. J.; Read, C. G.; Roske, C. W.; Lewis, N. S.; Schaak, R. E. Highly active electrocatalysis of the hydrogen evolution reaction by cobalt phosphide nanoparticles. Angew. Chem. 2014, 126, 55315534.

(8) Callejas, J. F.; Read, C. G.; Roske, C. W.; Lewis, N. S.; Schaak, R. E. Synthesis, Characterization, and Properties of Metal Phosphide Catalysts for the Hydrogen-Evolution Reaction. Chem. Mater. 2016, 28, 6017-6044.

(9) Sylvestre, J.-P.; Poulin, S.; Kabashin, A. V.; Sacher, E.; Meunier, M.; Luong, J. H. T. Surface Chemistry of Gold Nanoparticles Produced by Laser Ablation in Aqueous Media. J. Phys. Chem. B 2004, 108, 16864-16869.

(10) Bond, G. C. The origins of particle size effects in heterogeneous catalysis. Surf. Sci. 1985, 156, 966-981.

(11) Gupta, A. K.; Gupta, M. Synthesis and surface engineering of iron oxide nanoparticles for biomedical applications. Biomaterials 2005, 26, 3995-4021.

(12) Narayanan, R.; El-Sayed, M. A. Shape-Dependent Catalytic Activity of Platinum Nanoparticles in Colloidal Solution. Nano Lett. 2004, 4, 1343-1348.

(13) Zak, A. K.; Abrishami, M. E.; Majid, W. H. A.; Yousefi, R.; Hosseini, S. M. Effects of annealing temperature on some structural and optical properties of $\mathrm{ZnO}$ nanoparticles prepared by a modified sol-gel combustion method. Ceram. Int. 2011, 37, 393-398.

(14) Narayanan, R.; El-Sayed, M. A. Changing catalytic activity during colloidal platinum nanocatalysis due to shape changes: electron-transfer reaction. J. Am. Chem. Soc. 2004, 126, 7194-7195.

(15) Xie, R.; Cao, X.; Pan, Y.; Gu, H. Synthesis of Pt nanocatalysts for selective hydrogenation of ortho-halogenated nitrobenzene. Sci. China: Chem. 2015, 58, 1051-1055.

(16) Ye, L.; Zheng, J.; Tian, T.; Gao, Y.; Li, P. Preparation and Performance Study of an Unsupported Pt Catalyst for Proton Exchange Membrane Fuel Cell. ECS Meet. Abstr. 2015, 1590-1590.

(17) Tian, X. L.; Wang, L.; Deng, P.; Chen, Y.; Xia, B. Y. Research advances in unsupported Pt-based catalysts for electrochemical methanol oxidation. J. Energy Chem. 2017, 26, 1067-1076.

(18) Gralec, B.; Lewera, A. Catalytic activity of unsupported Pd-Pt nanoalloys with low Pt content towards formic acid oxidation. Appl. Catal., B 2016, 192, 304-310.

(19) Tian, X. L.; Xu, Y. Y.; Zhang, W.; Wu, T.; Xia, B. Y.; Wang, X. Unsupported Platinum-Based Electrocatalysts for Oxygen Reduction Reaction. ACS Energy Lett. 2017, 2, 2035-2043.

(20) Chi, N. Deposition and kinetics studies of platinum nanoparticles on highly oriented pyrolytic graphite; Open Dissertation Press, 2000.

(21) Kicela, A.; Daniele, S. Platinum black coated microdisk electrodes for the determination of high concentrations of hydrogen peroxide in phosphate buffer solutions. Talanta 2006, 68, 1632-1639.

(22) Kim, H.; Moon, S. H. Chemical vapor deposition of highly dispersed Pt nanoparticles on multi-walled carbon nanotubes for use as fuel-cell electrodes. Carbon 2011, 49, 1491-1501.

(23) Stonehart, P.; Ross, P. N. The Commonality of Surface Processes in Electrocatalysis and Gas-Phase Heterogeneous Catalysis. Catal. Rev.: Sci. Eng. 1975, 12, 1-35.

(24) McDonald, D.; Hunt, L. B. A History of Platinum and its Allied Metals; Johnson Matthey: London, 1982.

(25) Voorhees, V.; Adams, R. The use of the oxides of platinum for the catalytic reduction of organic compounds. I. J. Am. Chem. Soc. 1922, 44, 1397-1405.

(26) Mills, A. Final Analysis: Porous Platinum Morphologies: Platinised, Sponge and Black. Platinum Met. Rev. 2007, 51, 52-52.

(27) Larminie, J.; Dicks, A.; McDonald, M. S. Fuel cell systems explained, Vol. 2, Wiley: Chichester, U.K., 2003.

(28) McKee, D. Catalytic activity and sintering of platinum black. Kinetics of propane cracking. J. Phys. Chem. 1963, 67, 841-846.

(29) McKee, D. W. Catalytic decomposition of hydrogen peroxide by metals and alloys of the platinum group. J. Catal. 1969, 14, 355364.

(30) Simonsen, S. B.; Chorkendorff, I.; Dahl, S.; Skoglundh, M.; Sehested, J.; Helveg, S. Direct observations of oxygen-induced platinum nanoparticle ripening studied by in situ TEM. J. Am. Chem. Soc. 2010, 132, 7968-7975. 
(31) Tseung, A. C. C.; Dhara, S. C. Loss of surface area by platinum and supported platinum black electrocatalyst. Electrochim. Acta 1975, 20, 681-683.

(32) Bett, J.; Lundquist, J.; Washington, E.; Stonehart, P. Platinum crystallite size considerations for electrocatalytic oxygen reduction-I. Electrochim. Acta 1973, 18, 343-348.

(33) Lundquist, J. T.; Stonehart, P. Platinum crystallite size effects on oxide formation and reduction parameters-II. Electrochim. Acta 1973, 18, 349-354.

(34) Mills, A. Instrumental Note: Platinized Platinum, Platinum Sponge and Platinum Black. Bull.-Sci. Instrum. Soc. 2006, 89, 35.

(35) Adams, R.; Garvey, B. S. Selective reduction of citral by means of platinum-oxide platinum black and a promoter. J. Am. Chem. Soc. 1926, 48, 477-482.

(36) Stonehart, P.; Zucks, P. A. Sintering and recrystallization of small metal particles. Loss of surface area by platinum-black fuel-cell electrocatalysts. Electrochim. Acta 1972, 17, 2333-2351.

(37) Bregoli, L. J. The influence of platinum crystallite size on the electrochemical reduction of oxygen in phosphoric acid. Electrochim. Acta 1978, 23, 489-492.

(38) Paál, Z.; Tétényi, P. The mechanism of aromatization on platinum black catalyst; dehydrocyclization of hexadienes and hexatrienes. J. Catal. 1973, 30, 350-361.

(39) Paál, Z.; Zimmer, H.; Günter, J. R.; Schlögl, R.; Muhler, M. Sintering of platinum-black in hydrogen: Morphology and catalytic activity. J. Catal. 1989, 119, 146-160.

(40) Vogel, W.; Lundquist, L.; Ross, P.; Stonehart, P. Reaction pathways and poisons-II. Electrochim. Acta 1975, 20, 79-93.

(41) Ilic, B.; Czaplewski, D.; Neuzil, P.; Stanczyk, T.; Blough, J.; Maclay, G. J. Preparation and characterization of platinum black electrodes. J. Mater. Sci. 2000, 35, 3447-3457.

(42) Teshima, N.; Genfa, Z.; Dasgupta, P. K. Catalytic decomposition of hydrogen peroxide by a flow-through self-regulating platinum black heater. Anal. Chim. Acta 2004, 510, 9-13.

(43) Patel, P. R., Gibson, M. D., Ludwig, K. A.; Langhals, N. B. Electrochemical sensing via selective surface modification of iridium microelectrodes to create a platinum black interface, In Neural Engineering (NER), 2013 6th International IEEE/EMBS Conference 2013, 961-964, IEEE.

(44) Rosenbaum, M.; Schröder, U.; Scholz, F. Investigation of the electrocatalytic oxidation of formate and ethanol at platinum black under microbial fuel cell conditions. J. Solid State Electrochem. 2006, 10, 872-878.

(45) Fernandez, R. E.; Koklu, A.; Mansoorifar, A.; Beskok, A. Platinum black electrodeposited thread based electrodes for dielectrophoretic assembly of microparticles. Biomicrofluidics 2016, 10, 033101.

(46) Baird, T.; Paal, Z.; Thomson, S. J. Sintering studies on platinum black catalysts. Part 1.-Effect of pretreatment and reaction on particle size. J. Chem. Soc., Faraday Trans. 1 1973, 69, 50-55.

(47) Watkins, J. J.; Blackburn, J. M.; McCarthy, T. J. Chemical fluid deposition: reactive deposition of platinum metal from carbon dioxide solution. Chem. Mater. 1999, 11, 213-215.

(48) Paál, Z.; Muhler, M.; Schlögl, R. Platinum black by XPS. Surf. Sci. Spectra 1996, 4, 119-124.

(49) Rodriguez, N. M.; Anderson, P. E.; Wootsch, A.; Wild, U.; Schlögl, R.; Paál, Z. XPS, EM, and Catalytic Studies of the Accumulation of Carbon on Pt Black. J. Catal. 2001, 197, 365-377.

(50) Escobar Morales, B.; Gamboa, S. A.; Pal, U.; Guardián, R.; Acosta, D.; Magaña, C.; Mathew, X. Synthesis and characterization of colloidal platinum nanoparticles for electrochemical applications. Int. J. Hydrogen Energy 2010, 35, 4215-4221.

(51) Stepanov, A.; Golubev, A.; Nikitin, S. Synthesis and Applications of Platinum Nanoparticles: A Review. Nanotechnology: Synthesis and Characterization, Vol. 2;Studium Press: New Delhi, India, 2013; pp 173-199.

(52) Singal, S.; Srivastava, A. K.; Biradar, A. M.; Mulchandani, A.; Rajesh. Pt nanoparticles-chemical vapor deposited graphene compo- site based immunosensor for the detection of human cardiac troponin I. Sens. Actuators, B 2014, 205, 363-370.

(53) Oljaca, M.; Xing, Y.; Lovelace, C.; Shanmugham, S.; Hunt, A. Flame synthesis of nanopowders via combustion chemical vapor deposition. J. Mater. Sci. Lett. 2002, 21, 621-626.

(54) Komiyama, M.; Kobayashi, J. i.; Morita, S. Structure of platinum ultrafine particles in $\mathrm{Pt} / \mathrm{C}$ catalyst observed by scanning tunneling microscopy. J. Vac. Sci. Technol., A 1990, 8, 608-609.

(55) Kim, H.; Robertson, A. W.; Kim, S. O.; Kim, J. M.; Warner, J. $\mathrm{H}$. Resilient high catalytic performance of platinum nanocatalysts with porous graphene envelope. ACS Nano 2015, 9, 5947-5957.

(56) Eppell, S.; Chottiner, G. S.; Scherson, D. A.; Pruett, G. Scanning tunneling microscopy of platinum deposits on the basal plane of highly oriented pyrolytic graphite. Langmuir 1990, 6, 13161319.

(57) Lewis, L. N.; Stein, J.; Gao, Y.; Colborn, R. E.; Hutchins, G. Platinum catalysts used in the silicones industry. Platinum Met. Rev. 1997, 41, 66-75.

(58) Lee, S.; Permana, H.; Simon Ng, K. Y. Effects of annealing and gas treatment on the morphology of platinum cluster size on highly oriented pyrolytic graphite by scanning tunneling microscopy. Catal. Lett. 1994, 23, 281-292.

(59) Antoine, O.; Bultel, Y.; Durand, R. Oxygen reduction reaction kinetics and mechanism on platinum nanoparticles inside Nafion ${ }^{\circledR} . J$. Electroanal. Chem. 2001, 499, 85-94.

(60) Shao, M.; Peles, A.; Shoemaker, K. Electrocatalysis on Platinum Nanoparticles: Particle Size Effect on Oxygen Reduction Reaction Activity. Nano Lett. 2011, 11, 3714-3719.

(61) Han, B. C.; Miranda, C. R.; Ceder, G. Effect of particle size and surface structure on adsorption of $\mathrm{O}$ and $\mathrm{OH}$ on platinum nanoparticles: A first-principles study. Phys. Rev. B: Condens. Matter Mater. Phys. 2008, 77, 075410.

(62) Jaeger, N. I.; Jourdan, A. L.; Schulz-Ekloff, G. (1991) Effect of the size of platinum particles on the chemisorption of oxygen. J. Chem. Soc., Faraday Trans. 1991, 87, 1251-1257.

(63) Mukerjee, S. Particle size and structural effects in platinum electrocatalysis. J. Appl. Electrochem. 1990, 20, 537-548.

(64) Kinoshita, K. Particle size effects for oxygen reduction on highly dispersed platinum in acid electrolytes. J. Electrochem. Soc. 1990, 137, 845-848.

(65) Halperin, W. P. Quantum size effects in metal particles. Rev. Mod. Phys. 1986, 58, 533-606.

(66) Subramanian, V.; Wolf, E. E.; Kamat, P. V. Catalysis with $\mathrm{TiO}_{2} /$ Gold Nanocomposites. Effect of Metal Particle Size on the Fermi Level Equilibration. J. Am. Chem. Soc. 2004, 126, 4943-4950.

(67) Watanabe, M.; Sei, H.; Stonehart, P. The influence of platinum crystallite size on the electroreduction of oxygen. J. Electroanal. Chem. Interfacial Electrochem. 1989, 261, 375-387.

(68) Solliard, C.; Flueli, M. Surface stress and size effect on the lattice parameter in small particles of gold and platinum. Surf. Sci. 1985, 156, 487-494.

(69) Masson, A.; Bellamy, B.; Romdhane, Y. H.; Che, M.; Roulet, H.; Dufour, G. Intrinsic size effect of platinum particles supported on plasma-grown amorphous alumina in the hydrogenation of ethylene. Surf. Sci. 1986, 173, 479-497.

(70) Zhang, B.; Wang, D.; Hou, Y.; Yang, S.; Yang, X. H.; Zhong, J. H.; Liu, J.; Wang, H. F.; Hu, P.; Zhao, H. J.; Yang, H. G. Facetdependent catalytic activity of platinum nanocrystals for triiodide reduction in dye-sensitized solar cells. Sci. Rep. 2013, 3, 1836.

(71) Scheele-Ferreira, E. M.; Scott, C. E.; Perez-Zurita, M. J.; Pereira-Almao, P. R. Influence of the preparation variables on the synthesis of nanocatalyst for in-situ upgrading applications. Ind. Eng. Chem. Res. 2017, 56, 7131-7140.

(72) Zimicz, M. G.; Lamas, D. G.; Larrondo, S. A. Ce0.9Zr0.1O2 nanocatalyst: Influence of synthesis conditions in the reducibility and catalytic activity. Catal. Commun. 2011, 15, 68-73.

(73) Yaripour, F.; Shariatinia, Z.; Sahebdelfar, S.; Irandoukht, A. The effects of synthesis operation conditions on the properties of modified 
$\gamma$-alumina nanocatalysts in methanol dehydration to dimethyl ether using factorial experimental design. Fuel 2015, 139, 40-50.

(74) Stamenkovic, V. R.; Fowler, B.; Mun, B. S.; Wang, G.; Ross, P. N.; Lucas, C. A.; Marković, N. M. Improved Oxygen Reduction Activity on $\mathrm{Pt}_{3} \mathrm{Ni}(111)$ via Increased Surface Site Availability. Science 2007, 315, 493-497.

(75) Jiang, Q.; Liang, L. H.; Zhao, D. S. Lattice Contraction and Surface Stress of fcc Nanocrystals. J. Phys. Chem. B 2001, 105, 62756277.

(76) Deshpande, S.; Patil, S.; Kuchibhatla, S. V.; Seal, S. Size dependency variation in lattice parameter and valency states in nanocrystalline cerium oxide. Appl. Phys. Lett. 2005, 87, 133113.

(77) Krejci, D.; Woschnak, A.; Scharlemann, C.; Ponweiser, K. Structural impact of honeycomb catalysts on hydrogen peroxide decomposition for micro propulsion. Chem. Eng. Res. Des. 2012, 90, $2302-2315$

(78) Garwig, P. L. Heterogeneous decomposition of hydrogen peroxide by inorganic catalysts. A literature survey; FMC corp.: Princeton NJ, 1966.

(79) Ono, L. K.; Croy, J. R.; Heinrich, H.; Roldan Cuenya, B. Oxygen Chemisorption, Formation, and Thermal Stability of $\mathrm{Pt}$ Oxides on Pt Nanoparticles Supported on $\mathrm{SiO}_{2} / \mathrm{Si}(001)$ : Size Effects. J. Phys. Chem. C 2011, 115, 16856-16866.

(80) Nolan, P. D.; Wheeler, M. C.; Davis, J. E.; Mullins, C. B. Mechanisms of Initial Dissociative Chemisorption of Oxygen on Transition-Metal Surfaces. Acc. Chem. Res. 1998, 31, 798-804.

(81) Eley, D. D.; Macmahon, D. M. The decomposition of hydrogen peroxide catalysed by palladium-gold alloy wires. J. Colloid Interface Sci. 1972, 38, 502-510.

(82) Bianchi, G.; Mazza, F.; Mussini, T. Catalytic decomposition of acid hydrogen peroxide solutions on platinum, iridium, palladium and gold surfaces. Electrochim. Acta 1962, 7, 457-473.

(83) Chen, B.; Garland, N. T.; Geder, J.; Pruessner, M.; Mootz, E.; Cargill, A.; Leners, A.; Vokshi, G.; Davis, J.; Burns, W.; Daniele, M. A.; Kogot, J.; Medintz, I. L.; Claussen, J. C. Platinum Nanoparticle Decorated $\mathrm{SiO}_{2}$ Microfibers as Catalysts for Micro Unmanned Underwater Vehicle Propulsion. ACS Appl. Mater. Interfaces 2016, 8, 30941-30947.

(84) Marr, K. M.; Chen, B.; Mootz, E. J.; Geder, J.; Pruessner, M.; Melde, B. J.; Vanfleet, R. R.; Medintz, I. L.; Iverson, B. D.; Claussen, J. C. High Aspect Ratio Carbon Nanotube Membranes Decorated with Pt Nanoparticle Urchins for Micro Underwater Vehicle Propulsion via $\mathrm{H}_{2} \mathrm{O}_{2}$ Decomposition. ACS Nano 2015, 9, 7791-7803.

(85) Hammerschmidt, A.; Domke, W. D.; Nolscher, C.; Suchy, P. PEM fuel cell. U.S. Pat. US6010798A, 2000.

(86) Li, X.; Ge, S.; Hui, C.; Hsing, I.-M. Well-dispersed multiwalled carbon nanotubes supported platinum nanocatalysts for oxygen reduction. Electrochem. Solid-State Lett. 2004, 7, A286-A289.

(87) Li, Y.; Yang, J.; Song, J. Structure models and nano energy system design for proton exchange membrane fuel cells in electric energy vehicles. Renewable Sustainable Energy Rev. 2017, 67, 160-172.

(88) Nie, Y.; Li, L.; Wei, Z. Recent advancements in Pt and Pt-free catalysts for oxygen reduction reaction. Chem. Soc. Rev. 2015, 44, 2168-2201.

(89) Downs, R. T.; Hall-Wallace, M. The American Mineralogist crystal structure database. Am. Mineral. 2003, 88, 247-250.

(90) Birkholz, M.; Fewster, P. F.; Genzel, C. Thin Film Analysis by XRay Scattering; Wiley: Weinheim, Germany, 2006; DOI: 10.1002/ 3527607595.

(91) Mittemeijer, E. J., Scardi, P., Eds. Diffraction Analysis of the Microstructure of Materials; Springer: Berlin, Heidelberg, 2003.

(92) Suryanarayana, C.; Norton, M. G. X-ray diffraction: a practical approach; Springer Science \& Business Media: New York, 2013.

(93) Young, R. A. The Rietveld method, Vol. 5, International Union of Crystallography: Chester, U.K., 1993.

(94) Davis, S. M.; Somorjai, G. A. The effect of surface oxygen on hydrocarbon reactions catalyzed by platinum crystal surfaces with variable kink concentrations. Surf. Sci. 1980, 91, 73-91.
(95) Smith, C. E.; Biberian, J. P.; Somorjai, G. A. The effect of strongly bound oxygen on the dehydrogenation and hydrogenation activity and selectivity of platinum single crystal surfaces. J. Catal. 1979, 57, 426-443.

(96) Barr, T. L.; Seal, S. Nature of the use of adventitious carbon as a binding energy standard. J. Vac. Sci. Technol., A 1995, 13, 1239-1246.

(97) Kohiki, S.; Oki, K. Problems of adventitious carbon as an energy reference, J. Electron Spectrosc. J. Electron Spectrosc. Relat. Phenom. 1984, 33, 375-380.

(98) Evans, S. Correction for the effects of adventitious carbon overlayers in quantitative XPS analysis. Surf. Interface Anal. 1997, 25, 924-930.

(99) Piao, H.; McIntyre, N. Adventitious carbon growth on aluminium and gold-aluminium alloy surfaces. Surf. Interface Anal. 2002, 33, 591-594.

(100) Heister, K. The measurement of the specific surface area of soils by gas and polar liquid adsorption methods-Limitations and potentials. Geoderma 2014, 216, 75-87.

(101) Swift, P. Adventitious carbon-the panacea for energy referencing? Surf. Interface Anal. 1982, 4, 47-51.

(102) Blyth, R. I. R.; Buqa, H.; Netzer, F. P.; Ramsey, M. G.; Besenhard, J. O.; Golob, P.; Winter, M. XPS studies of graphite electrode materials for lithium ion batteries. Appl. Surf. Sci. 2000, 167, 99-106.

(103) Li, X.; Liu, M.; Lai, S. Y.; Ding, D.; Gong, M.; Lee, J.-P.; Blinn, K. S.; Bu, Y.; Wang, Z.; Bottomley, L. A.; Alamgir, F. M.; Liu, M. In situ probing of the mechanisms of coking resistance on catalystmodified anodes for solid oxide fuel cells. Chem. Mater. 2015, 27, $822-828$

(104) Yang, M.-L.; Zhu, Y.-A.; Fan, C.; Sui, Z.-J.; Chen, D.; Zhou, X.-G. DFT study of propane dehydrogenation on Pt catalyst: effects of step sites. Phys. Chem. Chem. Phys. 2011, 13, 3257-3267.

(105) Bai, L.; Zhou, Y.; Zhang, Y.; Liu, H.; Tang, M. Influence of Calcium Addition on Catalytic Properties of PtSn/ZSM-5 Catalyst for Propane Dehydrogenation. Catal. Lett. 2009, 129, 449.

(106) Huang, L.; Xu, B.; Yang, L.; Fan, Y. Propane dehydrogenation over the PtSn catalyst supported on alumina-modified SBA-15. Catal. Commun. 2008, 9, 2593-2597.

(107) Beuther, H.; Larson, O. A.; Perrotta, A. J. The Mechanism of Coke Formation on Catalysts. Stud. Surf. Sci. Catal. 1980, 6, 271-282, DOI: 10.1016/S0167-2991(08)65236-2.

(108) Guisnet, M.; Magnoux, P. Organic chemistry of coke formation. Appl. Catal., A 2001, 212, 83-96.

(109) Smith, C.; Biberian, J.; Somorjai, G. The effect of strongly bound oxygen on the dehydrogenation and hydrogenation activity and selectivity of platinum single crystal surfaces. J. Catal. 1979, 57, 426-443.

(110) Wintterlin, J.; Völkening, S.; Janssens, T. V. W.; Zambelli, T.; Ertl, G. Atomic and Macroscopic Reaction Rates of a SurfaceCatalyzed Reaction. Science 1997, 278, 1931-1934.

(111) Nesselberger, M.; Ashton, S.; Meier, J. C.; Katsounaros, I.; Mayrhofer, K. J. J.; Arenz, M. The Particle Size Effect on the Oxygen Reduction Reaction Activity of Pt Catalysts: Influence of Electrolyte and Relation to Single Crystal Models. J. Am. Chem. Soc. 2011, 133, $17428-17433$.

(112) Toyoda, E.; Jinnouchi, R.; Hatanaka, T.; Morimoto, Y.; Mitsuhara, K.; Visikovskiy, A.; Kido, Y. The d-Band Structure of Pt Nanoclusters Correlated with the Catalytic Activity for an Oxygen Reduction Reaction. J. Phys. Chem. C 2011, 115, 21236-21240.

(113) Bliznakov, G.; Lazarov, D. Surface heterogeneity of metals of the copper group in the catalytic decomposition of hydrogen peroxide. J. Catal. 1969, 14, 187-192.

(114) Mason, M. G. Electronic structure of supported small metal clusters. Phys. Rev. B: Condens. Matter Mater. Phys. 1983, 27, 748762.

(115) Roduner, E. Size matters: why nanomaterials are different. Chem. Soc. Rev. 2006, 35, 583-592. 
(116) Zhou, L.; Zachariah, M. R. Size resolved particle work function measurement of free nanoparticles: Aggregates vs. spheres. Chem. Phys. Lett. 2012, 525-526, 77-81.

(117) Parker, D. H.; Bartram, M. E.; Koel, B. E. Study of high coverages of atomic oxygen on the $\mathrm{Pt}(111)$ surface. Surf. Sci. 1989, 217, 489-510.

(118) Briot, P.; Auroux, A.; Jones, D.; Primet, M. Effect of particle size on the reactivity of oxygen-adsorbed platinum supported on alumina. Appl. Catal. 1990, 59, 141-152.

(119) Hammer, B.; Nørskov, J. K. Theoretical surface science and catalysis-calculations and concepts. Adv. Catal. 2000, 45, 71-129.

(120) Ciraci, S.; Batra, I. P. Theory of the quantum size effect in simple metals. Phys. Rev. B: Condens. Matter Mater. Phys. 1986, 33, 4294-4297.

(121) Jalan, V.; Taylor, E. Importance of interatomic spacing in catalytic reduction of oxygen in phosphoric acid. J. Electrochem. Soc. 1983, 130, 2299-2302.

(122) Appleby, A. Oxygen reduction on bright osmium electrodes in 85\% orthophosphoric acid. J. Electrochem. Soc. 1970, 117, 1157-1159.

(123) Shin, J.; Choi, J.-H.; Cha, P.-R.; Kim, S. K.; Kim, I.; Lee, S.-C.; Jeong, D. S. Catalytic activity for oxygen reduction reaction on platinum-based core-shell nanoparticles: all-electron density functional theory. Nanoscale 2015, 7, 15830-15839.

(124) Mills, A. Final Analysis: Porous Platinum Morphologies: Platinised. Platinum Met. Rev. 2007, 51, 52-52.

(125) Doebelin, N.; Kleeberg, R. Profex: a graphical user interface for the Rietveld refinement program BGMN. J. Appl. Crystallogr. 2015, 48, 1573-1580.

(126) Zhang, G.; Yang, D.; Sacher, E. X-ray Photoelectron Spectroscopic Analysis of Pt Nanoparticles on Highly Oriented Pyrolytic Graphite, Using Symmetric Component Line Shapes. J. Phys. Chem. C 2007, 111, 565-570.

(127) Parkinson, C. R.; Walker, M.; McConville, C. F. Reaction of atomic oxygen with a $\operatorname{Pt}\left(\begin{array}{lll}1 & 1 & 1\end{array}\right)$ surface: chemical and structural determination using XPS, CAICISS and LEED. Surf. Sci. 2003, 545, 19-33.

(128) Peuckert, M.; Yoneda, T.; Betta, R. A. D.; Boudart, M. Oxygen Reduction on Small Supported Platinum Particles. J. Electrochem. Soc. 1986, 133, 944-947.

(129) Mitchell, D. R. G. Circular Hough transform diffraction analysis: A software tool for automated measurement of selected area electron diffraction patterns within Digital Micrograph. Ultramicroscopy 2008, 108, 367-374.

(130) Serra-Maia, R.; Bellier, M.; Chastka, S.; Tranhuu, K.; Subowo, A.; Rimstidt, J. D.; Usov, P. M.; Morris, A. J.; Michel, F. M. Mechanism and Kinetics of Hydrogen Peroxide Decompostion on Platinum Nanocatalysts. ACS Appl. Mater. Interfaces 2018, DOI: 10.1021 /acsami.8b02345. 